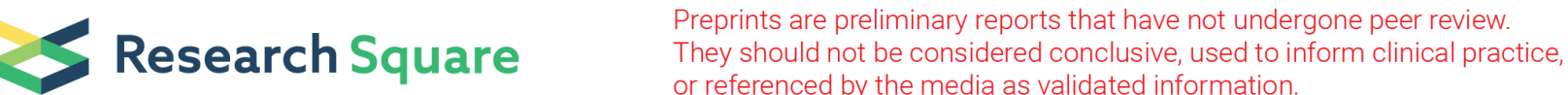

\section{Open Penetrating External Laryngotracheal Injury and Abdominal Trauma by Suicide Attempt Successfully Treated With Immediate Intervention: A Case Report}

Ryo Kamidani ( $\sim$ ryo.kami0125@gmail.com)

Gifu University School of Medicine Graduate School of Medicine: Gifu Daigaku Igakubu Daigakuin Igakukei Kenkyuka https://orcid.org/0000-0002-8478-9197

Hideshi Okada

Gifu university

Genki Yoshimura

Gifu university

Rina Kato

Gifu university

Keigo Kusuzawa

Gifu university

Masahiro Ichihashi

Gifu university

Yoshinori Kakino

Gifu university

Hideaki Oiwa

Gifu university

Ryu Yasuda

Gifu univesity

Yuichiro Kitagawa

Gifu university

Tetsuya Fukuta

Gifu university

Haruka Okamoto

Gifu university

Takahito Miyake

Gifu university

Masahito Tachi

Gifu university

Masato Shiba 
Gifu university

\section{Takesumi Nishihori}

Gifu university

\section{Bunya Kuze}

Gifu university

\section{Takahiro Yoshida}

Gifu university

\section{Shozo Yoshida}

Gifu university

\section{Shinji Ogura}

Gifu university

\section{Case report}

Keywords: penetrating external laryngotracheal injury, suicide, complete laryngotracheal separation, early wound closure

Posted Date: September 16th, 2020

DOI: https://doi.org/10.21203/rs.3.rs-76941/v1

License: (c) (i) This work is licensed under a Creative Commons Attribution 4.0 International License. Read Full License

Version of Record: A version of this preprint was published at Trauma Case Reports on April 1 st, 2021. See the published version at https://doi.org/10.1016/j.tcr.2021.100435. 


\section{Abstract}

Background: An open penetrating external laryngotracheal injury (LTI) is a rare life-threatening injury requiring immediate intervention. Penetrating injuries may cause tissue loss, which makes wound closure difficult sometimes. Here, we report the case of a patient who developed an open penetrating external LTI and abdominal trauma by suicide attempt, which required surgical intervention.

Case presentation: A 38-year-old Asian man with depression was found lying on the floor after cutting his neck and abdomen by himself. The emergency services found multiple deep lacerations on his anterior neck and abdomen. He was brought by a helicopter with a physician onboard to a regional trauma center and immediately intubated at the emergency department to secure his airway and prevent airway obstruction. On arrival, his blood pressure was $120 / 90 \mathrm{mmHg}$, and his heart rate was $120 \mathrm{beats} / \mathrm{min}$. A pre-shock status was presumed, but other vital signs were normal. Physical examination revealed cut wounds (three lines on the neck and two lines on the abdomen) and no dysphonia. The patient was diagnosed with an open penetrating external LTI, classified as group 5 on the Schaefer classification system and zone $\otimes$ on Roon and Christensen's modification. He was also suspected with a mesenteric injury. We performed an emergency primary laryngotracheal repair and exploratory laparotomy. There was no obvious blood vessel injury, but soft and cartilage tissues were crushed and disconnected completely. On day 8 , he underwent wound closure and tracheostomy on the caudal side of the wound. He was successfully weaned from mechanical ventilation on day 9 , transferred to the general ward on day 13 , decannulated on day 63 , and discharged from the hospital thereafter for subacute care.

Conclusions: This case was a severe neck injury with complete laryngotracheal separation, but tissue losses due to knife-stabbing were relatively minimal. Wound closure was presumed to occur early during primary repair, even though the purpose of primary repair was originally to secure the airway or manage blood vessel injury. Thus, in the absence of blood vessel injury, wound closure may occur early in patients who developed an open penetrating external LTI by suicide attempt.

\section{Background}

An open penetrating external laryngotracheal injury (LTI) is a rare life-threatening injury that requires immediate identification and intervention of the airway. As penetrating injuries are likely to cause tissue losses, wound closure is sometimes difficult to achieve. Here, we report the case of a patient who developed an open penetrating external LTI and abdominal trauma by suicide attempt, which required endotracheal intubation and surgical intervention.

\section{Case Presentation}

A 38-year-old Asian man with depression was found lying on the floor after cutting his neck and abdomen by himself at his house. A single-blade kitchen knife of average size was found on the floor. When emergency services arrived at the scene, they found multiple deep lacerations on his anterior neck and 
abdomen. The patient's airway was thought to be opened because his trachea was cut completely. While being transported, he was only treated with oxygen and intravenous fluid therapy. He was brought via a helicopter with a physician onboard to our hospital, a regional trauma center in Japan, and immediately intubated at the emergency department (ED) to secure the airway due to concerns of airway obstruction.

On arrival to the hospital, his blood pressure was $120 / 90 \mathrm{mmHg}$ without the use of catecholamine agonists, and his heart rate was 120 beats/min. He was presumed to be on a pre-shock status. His respiratory rate was 20 breaths $/ \mathrm{min}$, and his body temperature was $36.8^{\circ} \mathrm{C}$. While on controlled mechanical ventilation, he was on synchronized intermittent mandatory ventilation mode and had a tidal volume of $480 \mathrm{~mL}$, respiratory rate of 12 breaths/min, positive end-expiratory pressure of $5 \mathrm{cmH}_{2} \mathrm{O}$, pressure support of $5 \mathrm{cmH}_{2} \mathrm{O}$, and fraction of inspired oxygen of 0.40 . Physical examination revealed three lines of cut wound on his neck (transverse wound of $4 \mathrm{~cm}$ superior to the thyroid cartilage, $2 \mathrm{~cm}$ inferior to the thyroid cartilage, and $2 \mathrm{~cm}$ superior to the left sternoclavicular joint), two lines of cut wound on his abdomen (transverse wound of 3 and $2 \mathrm{~cm}$, reaching the peritoneum), and no dysphonia. However, no abnormal lesions were found on head and thoracic computed tomography (CT) at arrival, although increased CT attenuation indicating laryngotracheal rupture and mesenteric injuries were observed. Flexible nasal endoscopy was not enforced. A blood gas examination was performed, and the results are shown in Table 1. Meanwhile, the electrocardiogram, chest X-ray, and two-dimensional transthoracic echocardiography showed normal results.

The patient was diagnosed with an open penetrating external LTI, classified as group 5 on the Schaefer classification system, and was suspected with a mesenteric injury. He obtained an Injury Severity Scale score of 20, a Revised Trauma Score of 7.840, a probability of survival of 0.981 , and a Trauma and Injury Severity Score of 0.018 . He was admitted after undergoing emergency operations, namely, laryngotracheal repair and exploratory laparotomy. A team of ear, nose, and throat (ENT) doctors performed a primary repair of the thyroid cartilage, thyrohyoid bone, and epiglottis because they were crushed and disconnected. There was no obvious blood vessel injury. As there was no other obvious injury to repair, we only performed exploration, even though we suspected of mesenteric injury at the beginning. The patient was transferred to the intensive care unit, where he was transfused 2 units of red blood cell fluid and 4 units of fresh frozen plasma because his hemoglobin and fibrinogen count had decreased to 7.4 and $127 \mathrm{mg} / \mathrm{dL}$, respectively, due to hemorrhage and the emergency operations.

On day 8, he underwent wound closure and tracheostomy on the caudal side of the wound. He was successfully weaned from mechanical ventilation support on day 9 , transferred to the general ward on day 13 , decannulated on day 63 , and discharged from the hospital afterward for subacute care.

\section{Discussion And Conclusions}

An LTI can be classified as external or internal by direction of force, and an external LTI can be classified as open or close. External laryngeal injuries are estimated to occur at an incidence of 1 in every 13,7000 ED visits [1, 2]. The main mechanism of injury is thought to be due to falls or blunt trauma. In an 
epidemiological survey of head and neck injuries and trauma in the United States in $2011,64 \%$ of head and neck injuries were attributed to falls or blunt trauma and $41.8 \%$ of these were open wounds [3]. Penetrating neck injuries are less common and account for $5-10 \%$ of traumatic injuries in adults [4], although Sachdeva et al. showed that penetrating neck injuries are more common than blunt trauma [5]. Moreover, about $20 \%$ of LTIs are associated with other injuries [3]. Therefore, multiple traumatic injuries, including penetrating external LTIs, are quite rare and are managed only by a team by trauma specialists and otolaryngologists.

The initial assessment and management for neck injuries include a pre-hospital and a general trauma survey with primary consideration given to assessing and securing the airway. According to several studies, the most common symptoms of neck injury are respiratory distress, subcutaneous emphysema, hoarseness of voice, neck tenderness, stridor, dysphasia, and hemoptysis [6-9]. Patients need to be intubated immediately when signs of airway obstruction occur, such as increasing stridor, aphonia, and dyspnea with the use of accessory muscles of respiration $[2,10]$. However, the decision to intubate or not at the scene needs careful consideration because of the risk of mucosal soft tissue expansion and airway obstruction resulting from blind intubation. In a systematic review and meta-analysis of 21 studies, more than half of the studies showed that pre-hospital intubation was significantly associated with a higher mortality rate [11]. Thus, intubating the patient using bronchofiberscopy, which allows observation of the inner trachea, inserting a thinner endotracheal tube, and inserting a tracheostomy tube from the laceration remain to be much safer options. In our case, his airway was secured because there was no deviated tissue and blood clot which may obstruct airway due to complete laryngotracheal separation and no vessel injury. Therefore, the patient was transferred to the hospital without having been intubated.

In terms of the time course, a delayed definitive repair may result in higher chances of sequelae such as laryngeal stenosis, scarring, and granulation tissue formation. Hence, it must be performed ideally within 24 hours and no later than 48 hours after trauma $[12,13]$. Emergency physicians and trauma surgeons should also perform an initial assessment and management for severe conditions that may compromise the airway or breathing. Furthermore, in the event of securing the airway, a collaboration between ED and ENT doctors is necessary to improve patient evaluation and management. In our case, while it is true that the patient had no airway obstruction or blood vessel injury, the cooperation between ED and ENT doctors also had a significant impact on patient survival, even though the patient had multiple trauma.

A CT scan, especially a or CT angiography, is necessary for classifying the injury and choosing the treatment option. Although a penetrating external LTI usually requires surgical intervention for exploration and primary repair, treatment of blunt external or internal LTI depends on the severity of mucosal, cartilage, or bone injury. Therefore, a more detailed evaluation by a thin-slice scan and angiography is needed.

There are several classifications for LTI according to the severity, site (supraglottic, glottic, or subglottic), and tissue injured (cartilage, mucosa, ligaments, nerves, or joints). The American Academy of Otolaryngology-Head and Neck Surgery has accepted the Schaefer classification system as the most 
useful tool because it allows the clinician to make treatment decisions based on the severity of injury (Table 2) $[14,15]$. Under the Schaefer classification system, Group 1 injuries are usually managed using nonoperative methods, such as head elevation, voice rest, cool humidification, steroids, antibiotics, and anti-reflux medication. Although the frequency is different, tracheostomy is required for Group 2 to 4 injuries, while surgical repair is required for Group 3 and 4 injuries. For Group 5 injuries, although tracheostomy and surgical repair are also required, the main theme is only securing the airway and performing a primary repair. After that, a complex repair is often performed if the patient's general condition worsens. In our case, the patient's injuries were classified as Group 5 on the Schaefer classification system and were managed as mentioned above.

Table 2

Schaefer classification system

\begin{tabular}{|lll|}
\hline Group & Description of injury & $\begin{array}{l}\text { Method of } \\
\text { evaluation }\end{array}$ \\
\hline$\square$ & $\begin{array}{l}\text { Minor endolaryngeal hematomas or lacerations without detectable } \\
\text { fractures }\end{array}$ & $\begin{array}{l}\text { Flexible } \\
\text { laryngoscopy }\end{array}$ \\
\hline$\square \quad \begin{array}{l}\text { More severe edema, hematoma, minor mucosal disruption without } \\
\text { exposed cartilage, or non-displaced fractures }\end{array}$ & $\begin{array}{l}\text { Direct } \\
\text { laryngoscopy and } \\
\text { esophagoscopy }\end{array}$ \\
\hline$\square$ & $\begin{array}{l}\text { Direct } \\
\text { Massive edema, large mucosal lacerations, exposed cartilage, } \\
\text { displaced fractures or vocal cord immobility } \\
\text { esophagoscopy }\end{array}$ \\
\hline $\begin{array}{l}\text { Same as group 3, but more severe with disruption of anterior larynx, } \\
\text { unstable fractures, two or more fracture lines, or severe mucosal } \\
\text { injuries }\end{array}$ & $\begin{array}{l}\text { Direct } \\
\text { laryngoscopy and } \\
\text { esophagoscopy }\end{array}$ \\
\hline$\square$ & $\begin{array}{l}\text { Urgent airway } \\
\text { Comaluation }\end{array}$ \\
\hline
\end{tabular}

LTIs are also classified using Roon and Christensen's modification, which divides neck injuries into three zones according to anatomy. Zone $\otimes$ is from the level of the clavicles to that of the cricoid cartilage. Zone $\nabla$ is from the level of the cricoid cartilage to that of the angle of the mandible. Zone $\nabla$ covers from the level of the angle of the mandible to the base of the skull [16]. Although unstable patients require emergency surgical hemostasis and securing the airway, mandatory exploration is necessary for stable symptomatic

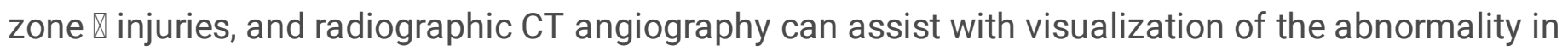
stable zone $\nabla$ and $\nabla$ injuries using zone-based management algorithm. However, zone $\nabla$ and $\nabla$ injuries are anatomically difficult to approach. Blunt LTIs require a thin-slice CT scan because they result in tissue disruptions instead of open wounds. Objects that cause penetrating injuries, such as a knife, bullet, fragment of iron or wood, and pen, are likely to cause more tissue loss than blunt injuries [3]. In particular, it is difficult to close wounds if there is loss of cartilage tissue. Although Pandurangarao et al. reported that cricoid cartilage defect could be repaired using conchal cartilage graft, the treatment can sometimes be long term [17]. Most penetrating injuries consist of a horizontal or oblique deep cut that results in an open wound, especially if it was a sharp and horizontal laceration due to a suicide attempt by knife- 
stabbing $[3,18]$. In our case, wound closure was presumed to occur at a comparatively early time because despite the occurrence of complete laryngotracheal separation, the sharp and horizontal lacerations were not accompanied by significant tissue losses. Although jugular vein or vertebral artery injuries are common with neck injuries, the findings from our case indicate that wound closure may occur early in patients who attempted suicide by knife-stabbing and developed an open penetrating external LTI without blood vessel injuries. Thus, a need arises for a new classification that considers the sharpness of the wound, the degree of tissue loss and disruption, and the nature of the object that caused the injury.

\section{List Of Abbreviations}

CT: computed tomography

ED: emergency department

ENT: ears, nose, and throat

LTI: laryngotracheal injury

\section{Declarations}

\section{Ethics approval and consent to participate}

The need for ethics approval was waived as per the national guidelines. The study adhered to the Ethical Guidelines for Medical and Health Research Involving Human Subjects, established by the government of Japan.

\section{Consent for publication}

Written informed consent was obtained from the patient for the publication of this case report and any accompanying images.

\section{Availability of data and materials}

The datasets during and/or analyzed during the current study available from the corresponding author on reasonable request.

\section{Competing interests}

The authors declare that they have no competing interests.

\section{Funding}

None

\section{Authors' contributions}


R.Kamidani, H.Okada, G.Y., R.Kato, K. K., M.I., Y. Kakino, H. Oiwa, R.Y., Y. Kitagawa, T.F., H. Okamoto, T.M., M.T., M.S., T.N., B.Z., T.Y., S.Y. and S.O treated the patient. R. Kamidani wrote the manuscript and H.Okada revised and edited the manuscript. All authors read and approved the final manuscript.

\section{Acknowledgments}

We would like to thank Editage (www.editage.com) for English language editing.

\section{References}

1. Jewett BS, Shockley WW, Rutledge R. External laryngeal trauma analysis of 392 patients. Arch Otolaryngol Head Neck Surg. 1999;125:877-80.

2. Hussain SM. Logan Turner's diseases of the nose, throat and ear: head and neck surgery. 11th ed. London: CRC Press; 2015.

3. Parida PK, Kalaiarasi R, Alexander A. Management of laryngotracheal trauma: a five-year single institution experience. Iran J Otorhinolaryngol. 2018;30:283-90.

4. Demetriades D, Skalkides J, Sofianos C, Melissas J, Franklin J. Carotid artery injuries: experience with 124 cases. J Trauma. 1989;29:91-4.

5. Sachdeva K, Upadhyay A. Neck trauma: ENT prospects. Indian J Otolaryngol Head Neck Surg. 2017;69:52-7.

6. Schaefer SD. The treatment of acute external laryngeal injuries. "State of the art". Arch Otolaryngol Head Neck Surg. 1991;117:35-9.

7. Yen PT, Lee HY, Tsai MH, Chan ST, Huang TS. Clinical analysis of external laryngeal trauma. J Laryngol Otol. 1994;108:221-5.

8. Cherian TA, Rupa V, Raman R. External laryngeal trauma: analysis of thirty cases. J Laryngol Otol. 1993;107:920-3.

9. Akhtar S, Awan S. Laryngotracheal trauma: its management and sequelae. J Pak Med Assoc. 2008;58:241-3.

10. Fuhrman GM, Stieg FH 3rd, Buerk CA. Blunt laryngeal trauma: classification and management protocol. J Trauma. 1990;30:87-92.

11. Fevang E, Perkins Z, Lockey D, Jeppesen E, Lossius HM. A systematic review and meta-analysis comparing mortality in pre-hospital tracheal intubation to emergency department intubation in trauma patients. Crit Care. 2017;21:192.

12. Bell RB, Verschueren DS, Dierks EJ. Management of laryngeal trauma. Oral Maxillofac Surg Clin North Am. 2008;20:415-30.

13. Bent JP 3rd, Silver JR, Porubsky ES. Acute laryngeal trauma: a review of 77 patients. Otolaryngol Head Neck Surg. 1993;109:441-9.

14. Moonsamy P, Sachdeva UM, Morse CR. Management of laryngotracheal trauma. Ann Cardiothorac Surg. 2018;7:210-6. 
15. Schaefer SD. The acute management of external laryngeal trauma. A 27-year experience. Arch Otolaryngol Head Neck Surg. 1992;118:598-604.

16. Roon AJ, Christensen N. Evaluation and treatment of penetrating cervical injuries. J Trauma. 1979;19:391-7.

17. Pandurangarao SU, Basavaraj $P$, Yempalle SB, Karnam L. Primary management and outcome - open laryngotracheal trauma. J Clin Diagn Res. 2017;11:MR01-4.

18. Iseh KR, Obembe A. Anterior neck injuries presenting as cut throat emergencies in a tertiary health institution in north western Nigeria. Niger J Med. 2011;20:475-8.

\section{Tables}

Due to technical limitations, table 1 is only available as a download in the Supplemental Files section.

\section{Figures}

(A)

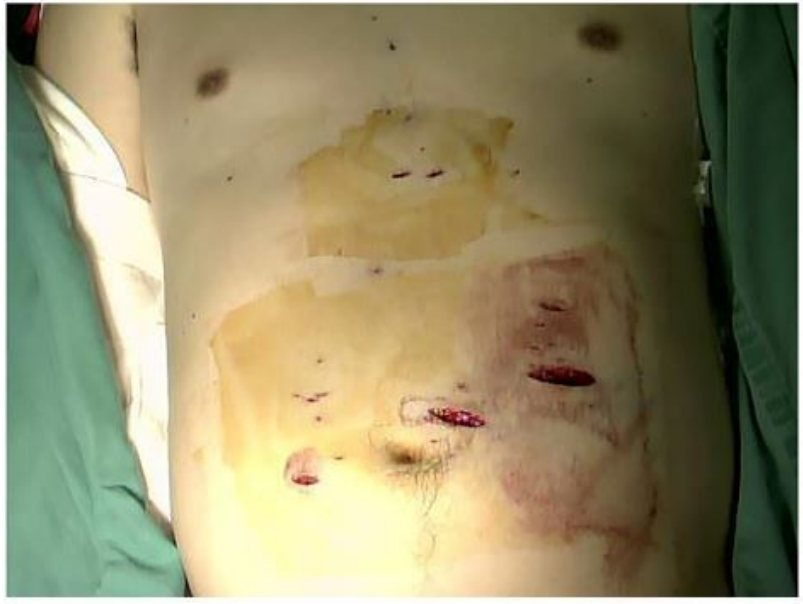

(C)

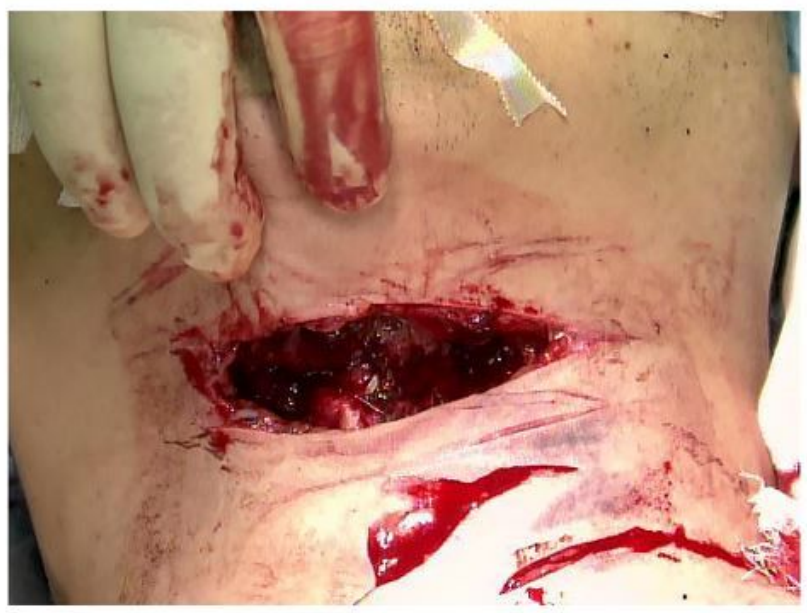

(B)

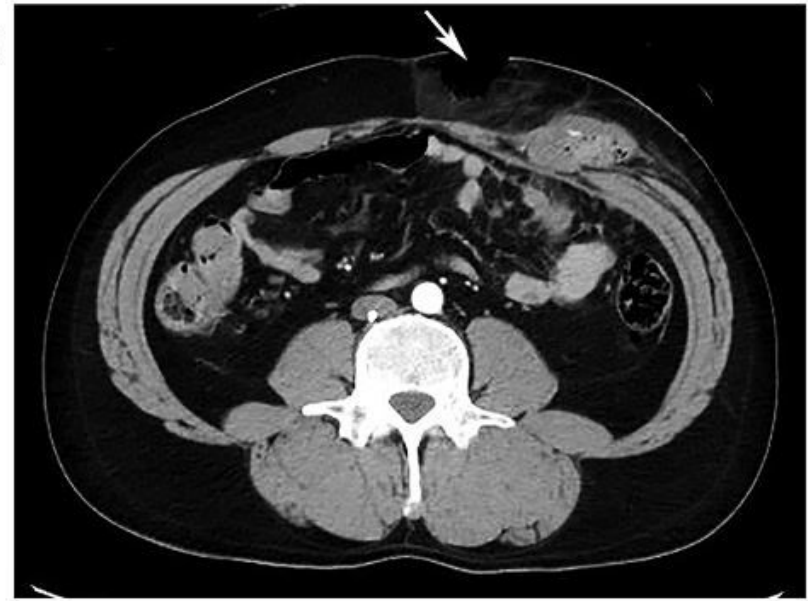

(D)

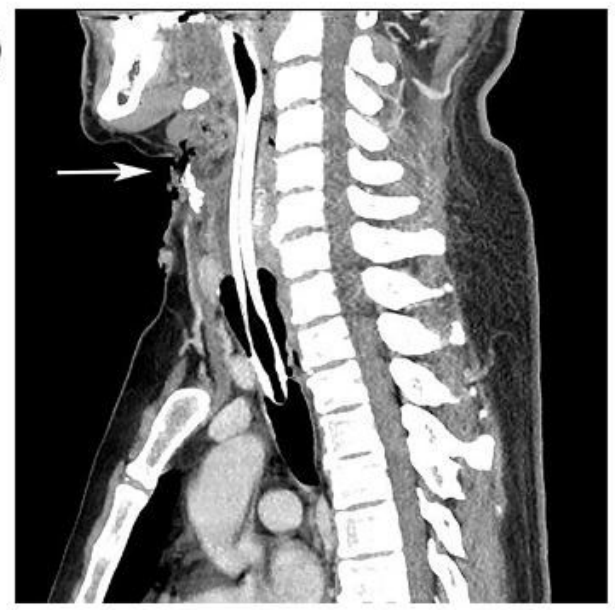

Figure 1 
(A) Two lines of cut wound on his abdomen (transverse wound of 3 and $2 \mathrm{~cm}$ ). (B)2-dimentional axial CT showed the increased CT value of panniculitis and deep lacerations reaching the peritoneum. (C) Three lines of cut wound on his neck (transverse wound of $4 \mathrm{~cm}$ superior to the thyroid cartilage, $2 \mathrm{~cm}$ inferior to the thyroid cartilage, and $2 \mathrm{~cm}$ superior to the left sternoclavicular joint). (D) 2-dimentional sagittal CT showed significant subcutaneous emphysema at the level of hyoid bone.
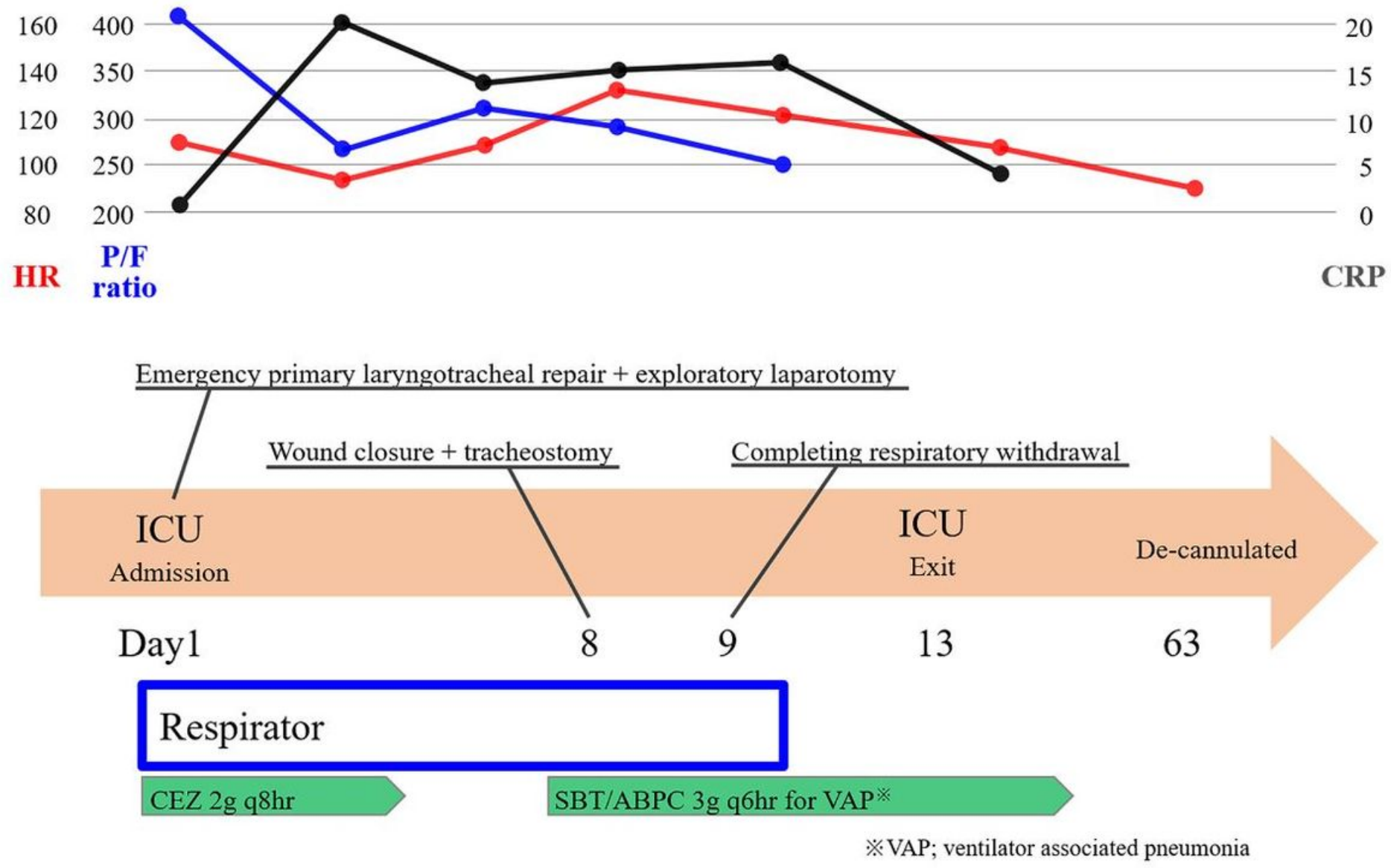

Figure 2

Clinical Course

\section{Supplementary Files}

This is a list of supplementary files associated with this preprint. Click to download.

- Table1.JPG 